\title{
Bowel Obstruction and Perforation in Pediatric Intestinal Mature B Cell Lymphoma: Incidence, Clinical Features, and Outcome in CCHE
}

\author{
Samah Fathy Semary 1, 2, *, Hany Abdel Rahman 2,3, Gehad Ahmed ${ }^{4,5}$, Naglaa EI Kenaie ${ }^{6,7}$, \\ Marwa Romeih ${ }^{8,9}$, Rana Mohy ${ }^{10}$, Nouran Nagi ${ }^{10}$ \\ ${ }^{1}$ Department of Clinical Oncology, Faculty of Medicine, Beni - Suef University, Beni- Suef, Egypt \\ ${ }^{2}$ Department of Pediatric Oncology, Children Cancer Hospital Egypt, Cairo, Egypt \\ ${ }^{3}$ Department of Pediatric Oncology, National Cancer Institute, Cairo University, Cairo, Egypt \\ ${ }^{4}$ Department of Surgery, Helwan University, Cairo, Egypt \\ ${ }^{5}$ Department of Surgery, Children Cancer Hospital Egypt, Cairo, Egypt \\ ${ }^{6}$ Department of Pathology, National Cancer Institute, Cairo University, Cairo, Egypt \\ ${ }^{7}$ Department of Pathology, Children Cancer Hospital Egypt, Cairo, Egypt \\ ${ }^{8}$ Department of Radio-Diagnosis, Helwan University, Cairo, Egypt \\ ${ }^{9}$ Department of Radio-Diagnosis, Children Cancer Hospital Egypt, Cairo, Egypt \\ ${ }^{10}$ Department of Clinical Research, Children Cancer Hospital Egypt, Cairo, Egypt
}

\section{Email address:}

samahsemary@yahoo.com (S. F. Semary), samah.semary@57357.com (S. F. Semary)

${ }^{*}$ Corresponding author

\section{To cite this article:}

Samah Fathy Semary, Hany Abdel Rahman, Gehad Ahmed, Naglaa El Kenaie, Marwa Romeih, Rana Mohy, Nouran Nagi. Bowel Obstruction and Perforation in Pediatric Intestinal Mature B Cell Lymphoma: Incidence, Clinical Features, and Outcome in CCHE. Cancer Research Journal. Vol. 7, No. 2, 2019, pp. 45-52. doi: 10.11648/j.crj.20190702.13

Received: March 19, 2019; Accepted: April 17, 2019; Published: May 26, 2019

\begin{abstract}
Bowel perforation or obstruction is life-threatening complications of intestinal lymphoma. Our aim was to define incidence, clinical features, and outcome associated with bowel perforation or obstruction in pediatric intestinal lymphoma. A retrospective, non-randomized study was included all newly diagnosed pediatric intestinal mature B cell lymphoma patients who were operated out of intestinal obstruction or perforation from July 2007 till July 2017 in CCHE. The results showed that, intestinal obstruction or perforation developed in 34 patients (7.5\%) out of 456 patients with intestinal mature B cell lymphoma. Median age is 4.85 years. All of them were treated accordingly to NHL LMB 96 protocol [1]. The 5 years OS among patients were operated out of intestinal obstruction, and who were operated out of perforation were $87.7 \%, 62.9 \%$ respectively with no significant statistical differences. Five years OS among patients with viable malignant cell versus no malignant cell was $65.2 \%$, $90.9 \%$ respectively with significant $\mathrm{P}$ value. The five years OS for patients didn't have surgery, and who had surgery was $87.9 \%, 78.6 \%$, respectively, with no significant statistical differences. Multivariate analysis on EFS and OS was done for the overall group and the subgroup. Including age, sex, pathology, clinical stage, elevated LDH, presence of ATLS, showed statically no significance. In Conclusion, Intestinal complication in the form of obstruction with or without intussusception, or obstruction perforation followed by exploration is not adverse prognostic factor for survival in pediatric patients with intestinal mature B cell lymphoma. Operation with viable malignant cell was associated with significant lower outcome.
\end{abstract}

Keywords: Bowel Obstruction, Bowel Perforation, Prognostic Factors, Pediatric Intestinal Mature B Cell Lymphoma 


\section{Introduction}

Burkitt's lymphoma (BL) is a highly malignant, aggressive and rapidly growing B-cell neoplasm. The abdomen is the most frequent site in sporadic BL [2]. Typically presents with an abdominal mass or ascites. Perforation and obstruction are serious life-threatening complications of lymphoma involving the gastrointestinal tract [3]. Intestinal obstruction or intussusception is caused by pressure phenomena, direct involvement of the bowel lumen or occur after initiation of chemotherapy.

\section{Aim of the Work}

Was to define incidence, clinical features, and outcome associated with bowel perforation and/or obstruction in pediatric intestinal mature B cell lymphoma

\section{Patients and Methodology}

A single center retrospective, non-randomized study was done. All newly diagnosed intestinal mature $\mathrm{B}$ cell lymphoma (BL, or diffuse large B cell lymphoma (DLBCL)) patients less than 18 years old who were complicated and operated out of intestinal obstruction or perforation were included from July 2007 till end of July 2017 in Children Cancer Hospital Egypt (CCHE).

Patients were treated according to NHL LMB - 96 Protocol [1]. Median follow up was 35 months with range 4 to 99 months.

Eligible patients were less than 18 years old, had de novo intestinal mature $\mathrm{B}$ cell lymphoma (BL, or DLBCL) confirmed by pathological diagnostic methods. Initial work up included full laboratory tests, computed tomographic scans for the whole body, and a bone marrow aspirate and bilateral bone marrow biopsy. All the patients 'legal guardians provided written informed consent. We compared between the patients who were complicated and operated as the result of intestinal obstruction with or without intussusception, and who were complicated and operated due to intestinal obstruction and perforation. Compare between the patients who were complicated and operated with positive versus negative viable tissue for malignancy by pathology. And finally compare between the outcome of patients with mature B cell lymphoma who were complicated and operated versus who did not have surgery.

\section{Statistical Analysis}

The Kaplan-Meier method was used to estimate overall survival, and event free survival for all groups of the study. OS was defined as time from study entry till end of the study or death. EFS were defined as time from study entry till remission failure or relapse whereby patients who died as a result of causes other than $\mathrm{BL}$ were competing events. Multivariate analysis of prognostic factors for bowel obstruction and / or perforation on event-free survival and overall survival was done

\section{Result}

A total of 34 patients (7.5\%) had surgery as the result of intestinal obstruction and/or perforation (the subgroup patients) out of 456 patients with intestinal mature B cell Lymphoma (the overall group patients) enrolled between July 2007 and end of July 2017 at CCHE. Twenty two patients $(64.7 \%)$ were males and $12(35.3 \%)$ were females compared to 355 patients $(77.9 \%)$ were male and $101(22.1 \%)$ female among the overall group, table 1 . The mean age was 5.8 years $(95 \% \mathrm{cl})$ and the median age was 4.85 years, range 2.8 to 15.7 years among the subgroup patients. The median age was 5.51 years among the overall group. All the patients of the subgroup were diagnosed by pathology as Burkitt's lymphoma.

According to Ann Arbor staging, 4 patients (11.8\%) had stage I I, while 26 patients $(76.5 \%)$ had stage III and only 4 patients $(11.8 \%)$ were stage IV for central nervous system (CNS) or bone marrow involvement (BM), compared to the overall group there were 81 patients $(17.8 \%)$ had stage II, 328 patients $(71.9 \%)$ were stage III, and 47 patients $(10.3 \%)$ were stage IV, table 1 , with no significant statistical difference.

Among the subgroup patients lactate dehydrogenase (LDH) was double the normal value $(\geq 2 \times$ upper limit of normal [ULN]) in 10 patients $(29.4 \%)$ and was double the normal value in 199 patients (43.6\%) in the overall group with no significant $\mathrm{p}$ value. Tumor lysis syndrome was detected in 6 patients $(17.7 \%)$ among the subgroup patients, and was detected in 73 patients (16\%) among the overall group with no significant statistical difference table 1 .

All the thirty four patients were treated accordingly to NHL LMB 96 protocol [1], two patients (5.9\%) were treated as group A (completely excised, _ve lymph nodes, _ve surgical margin) and received only 2 cycles of COPADD. Twenty eight patients $(82.4 \%)$ were treated as group B, 4 patients $(11.8 \%)$ were treated as group $\mathrm{C}$ due to $\mathrm{CNS}$ or BM involvement. Also the overall group was treated according to NHL LMB 96 protocol in the frequency of 29 patients $(6.4 \%)$ as group A, 384 patients (84.2\%) as group B, and 39 patients $(8.6 \%)$ as group $\mathrm{C}$ with no significant statistical differences, table 1.

Small intestine was the site of initial presentation and of intestinal complication in all subgroup patients. Fourteen patients $(41.2 \%)$ out of the 34 patients were complicated with obstruction, $6(17.6 \%)$ had obstruction associated with intussusception, and 14 patients (41.2\%) were complicated with obstruction and perforation. Among the 14 patients who complicated with perforation, presented with severe abdominal pain, and repeated vomiting, computerized tomography (CT) was done. Seven patients of them (50\%) were with $\mathrm{CT}$ finding in the form of impending perforation, 10 of them $(71.4 \%)$ were presented initially at time of diagnosis by aneurysmal dilatation, 11 patients $(78.6 \%)$ were presented at time of perforation by pneumo peritonium and 
free abdominal fluid, 8 of patients with perforation (57.1\%) had proximal dilatation and distal collapse. Small bowel fecal matter was presented in 6 patients $(42.9 \%)$, and bowel wall air (gangrenous loop) was present in one patient $(7.1 \%)$, table 3 , all of this finding with no significant $\mathrm{P}$ value as a factor of impending perforation, table 4. Exploration and resection anastomosis were done for all the subgroup patients.

The overall survival among the patients who were operated for obstruction with or without intussusception versus the patients who were operated for obstruction and perforation were $87.7 \%, 62.9 \%$ respectively with $\mathrm{P}$ value 0.08 . The event free survival among the 2 groups was $75.1 \%, 53.6 \%$ respectively with $P$ value 0.153 , table 5, figure 1 .

Five patients $(14.7 \%)$ were operated at time of diagnosis (pretreatment), 5 patients $(14.7 \%)$ were operated at pre phase (CVP), 12 patients $(35.3 \%)$ during induction phase, 6 patients $(14.6 \%)$ during consolidation phase, one patient $(2.9 \%)$ during maintenance phase of treatment, 2 patients $(5.9 \%)$ were operated post end of treatment while there were under follow up, 3 patients $(8.82 \%)$ were operated at time of relapse, table 2 . The median time of delay of chemotherapy because of exploration was 22 days with range 3-37 days.

Pathology was done for all resected intestinal loops, sixteen patients $(47.1 \%)$ had viable tissue, and 18 patients $(52.9 \%)$ had no malignant tissue. The five years overall survival among the patients with positive viable tissue versus whom with negative viable tissue was $65.2 \%, 90.9 \%$ respectively with significant $P$ value 0.049 . The 5 years event free survival among these 2 groups was $48.2 \%, 88.9 \%$ respectively with $\mathrm{p}$ value 0.059 , table 6 , figure 2 .

Five patients out of 34 patients (14.7\%) relapsed or had progressive disease. Among the three relapsed patients $(8.8 \%), 2$ of them $(5.8 \%)$ had autologous BMT and are alive in CR, 1 patient (2.9\%) relapsed and died in active disease with median time of relapse 44.967 months. Two patients $(5.8 \%)$ died out of progressive disease. Among the overall group 15 patients $(3.3 \%)$ were relapsed with median time of relapse 45.3 months, and 20 patients $(4.4 \%)$ were suffering from progressive disease, table 1.

Six patients $(17.6 \%)$ out of the 34 patients died, and 28 patients $(82.4 \%)$ were alive and in complete remission. Among the patients who died, 3 of them $(8.8 \%)$ died out of disease progression, 3 of them $(8.8 \%)$ died out of operative complications, one of them $(2.9 \%)$ died in induction and the rest $(5.8 \%)$ died in pre phase. Fifty three patients $(11.6 \%)$ among the overall group were died, table 1.

Five years OS for intestinal mature B cell lymphoma patients who didn't have surgery and among who had surgery out of intestinal obstruction or perforation was $87.9 \% \mathrm{SE}=0.016$, $78.6 \%, \mathrm{SE}=0.080$, respectively with $\mathrm{p}$ value 0.323 figure 9. the EFS among these 2 groups was $85.4 \% \mathrm{SE}=0.017,67.2 \%, \mathrm{SE}=$ 0.097 , respectively with $\mathrm{p}$ value 0.055 , table 7 , figure 3 .

Table 1. Study group patient's characteristics.

\begin{tabular}{|c|c|c|c|c|c|c|}
\hline & & \multicolumn{2}{|c|}{ No surgery (456) } & \multicolumn{2}{|c|}{ Surgery (34) } & \multirow{2}{*}{ P-value } \\
\hline & & Count & $\%$ & Count & $\%$ & \\
\hline \multirow{2}{*}{ Gender } & Female & 101 & $22.1 \%$ & 12 & $35.3 \%$ & \multirow{3}{*}{0.079} \\
\hline & Male & 355 & $77.9 \%$ & 22 & $64.7 \%$ & \\
\hline \multirow{4}{*}{ Mature B } & Burkitt's Leukemia & 13 & $2.9 \%$ & 1 & $2.9 \%$ & \\
\hline & Burkitt's Lymphoma & 435 & $95.4 \%$ & 33 & $97.1 \%$ & \multirow{3}{*}{1} \\
\hline & Diffuse large B cell Lymphoma & 7 & $1.5 \%$ & & & \\
\hline & Mature B NHL NOS & 1 & $.2 \%$ & & & \\
\hline \multirow{2}{*}{ Bone Marrow Involved } & No & 426 & $93.4 \%$ & 32 & $94.1 \%$ & \multirow{2}{*}{1} \\
\hline & Yes & 30 & $6.6 \%$ & 2 & $5.9 \%$ & \\
\hline \multirow{2}{*}{ CNS Involved } & No & 431 & $94.5 \%$ & 32 & $94.1 \%$ & \multirow{2}{*}{0.71} \\
\hline & Yes & 25 & $5.5 \%$ & 2 & $5.9 \%$ & \\
\hline \multirow{4}{*}{ Modified Murphy Staging } & Stage I & 5 & $1.1 \%$ & 3 & $8.8 \%$ & \multirow{5}{*}{0.035} \\
\hline & Stage II & 81 & $17.8 \%$ & 4 & $11.8 \%$ & \\
\hline & Stage III & 323 & $70.8 \%$ & 23 & $67.6 \%$ & \\
\hline & Stage IV & 47 & $10.3 \%$ & 4 & $11.8 \%$ & \\
\hline \multirow{4}{*}{ Group } & R-CHOP & 4 & $.9 \%$ & 0 & & \\
\hline & Group A & 29 & $6.4 \%$ & 2 & $5.9 \%$ & \multirow{3}{*}{0.814} \\
\hline & Group B & 384 & $84.2 \%$ & 28 & $82.4 \%$ & \\
\hline & Group C & 39 & $8.6 \%$ & 4 & $11.8 \%$ & \\
\hline \multirow{3}{*}{ LDH } & High $>2$ UL & 199 & $43.6 \%$ & 10 & $29.40 \%$ & \multirow{3}{*}{0.27} \\
\hline & higher than $600<2 \mathrm{UL}$ & 95 & $20.8 \%$ & 9 & $26.50 \%$ & \\
\hline & Normal & 162 & $35.5 \%$ & 15 & $44.10 \%$ & \\
\hline \multirow{3}{*}{$\begin{array}{l}\text { Tumor Lysis Syndrome } \\
\text { (TLS) }\end{array}$} & NA & 79 & $17.3 \%$ & 8 & $23.50 \%$ & \multirow{3}{*}{0.597} \\
\hline & No & 304 & $66.7 \%$ & 20 & $58.80 \%$ & \\
\hline & Yes & 73 & $16.0 \%$ & 6 & $17.70 \%$ & \\
\hline \multirow{2}{*}{ Alive/Dead } & Alive & 403 & $88.4 \%$ & 28 & $82.40 \%$ & \multirow{2}{*}{0.279} \\
\hline & Dead & 53 & $11.6 \%$ & 6 & $17.60 \%$ & \\
\hline \multirow{3}{*}{$\begin{array}{l}\text { Did the patient suffer from } \\
\text { progression/ recurrence? }\end{array}$} & No & 421 & $92.3 \%$ & 29 & $85.30 \%$ & \multirow{2}{*}{0.183} \\
\hline & Yes & 35 & $7.7 \%$ & 5 & $14.70 \%$ & \\
\hline & No progression / relapse & 421 & $92.3 \%$ & 29 & $85.30 \%$ & \multirow{3}{*}{0.141} \\
\hline \multirow[t]{2}{*}{ Type } & Progression & 20 & $4.4 \%$ & 2 & $5.90 \%$ & \\
\hline & Recurrence (Relapse) & 15 & $3.3 \%$ & 3 & $8.80 \%$ & \\
\hline
\end{tabular}


Table 2. Time of operation in relation to protocol of chemotherapy.

\begin{tabular}{lll}
\hline PHASE OF TTT & NUMBER OF PATIENTS & PERCENT \\
\hline PRE TREATMENT & 5 & $14.7 \%$ \\
IN PRE PHASE CVP & 5 & $14.7 \%$ \\
INDUCTION & 12 & $35.3 \%$ \\
CONSOLIDATION & 6 & $17.5 \%$ \\
MAINTENANCE & 1 & $2.9 \%$ \\
POST END OF TREATMENT & 2 & $5.9 \%$ \\
AT RELAPSE/ PROGRESSION & 3 & $8.82 \%$ \\
TOTAL & 34 & $100 \%$ \\
\hline
\end{tabular}

Table 3. Perforation characteristics.

\begin{tabular}{|c|c|c|c|}
\hline & & Count & $\mathbf{N} \%$ \\
\hline \multirow{2}{*}{ Impending perforation } & no & 7 & $50.0 \%$ \\
\hline & yes & 7 & $50.0 \%$ \\
\hline \multirow{2}{*}{ aneurysmal dilation intial (yes/no) } & no & 4 & $28.6 \%$ \\
\hline & yes & 10 & $71.4 \%$ \\
\hline \multirow{2}{*}{ pnumopertinouem } & no & 3 & $21.4 \%$ \\
\hline & yes & 11 & $78.6 \%$ \\
\hline free fluid & no & 3 & $21.4 \%$ \\
\hline \multirow{2}{*}{ Proximal diltation } & no & 6 & $42.9 \%$ \\
\hline & yes & 8 & $57.1 \%$ \\
\hline \multirow{2}{*}{ distal collapse } & no & 6 & $42.9 \%$ \\
\hline & yes & 8 & $57.1 \%$ \\
\hline \multirow{2}{*}{ small bowel fecal matter } & no & 8 & $57.1 \%$ \\
\hline & yes & 6 & $42.9 \%$ \\
\hline \multirow{2}{*}{ bowel wall air (gangaeren) } & no & 13 & $92.9 \%$ \\
\hline & yes & 1 & $7.1 \%$ \\
\hline
\end{tabular}

Table 4. Statistical tests (factors for impending perforation).

\begin{tabular}{|c|c|c|c|c|}
\hline & & & & P-Value \\
\hline & & aneurysmal dilation intial (yes/no) & & \\
\hline & & no & yes & \multirow{4}{*}{0.559} \\
\hline \multirow{3}{*}{ Impending perforation } & no & 3 & 4 & \\
\hline & yes & 1 & 6 & \\
\hline & & pneumopertitonium & & \\
\hline \multirow{4}{*}{ Impending perforation } & & no & yes & \multirow{4}{*}{0.192} \\
\hline & no & 3 & 4 & \\
\hline & yes & 0 & 7 & \\
\hline & & free fluid & & \\
\hline \multirow{4}{*}{ Impending perforation } & & no & yes & \multirow{3}{*}{0.192} \\
\hline & no & 3 & 4 & \\
\hline & yes & 0 & 7 & \\
\hline & & Proximal diltation & & \\
\hline \multirow{4}{*}{ Impending perforation } & & no & yes & \multirow{3}{*}{1} \\
\hline & no & 3 & 4 & \\
\hline & yes & 3 & 4 & \\
\hline & & distal collapse & & \\
\hline \multirow{4}{*}{ Impending perforation } & & no & yes & \multirow{4}{*}{1} \\
\hline & no & 3 & 4 & \\
\hline & yes & 3 & 4 & \\
\hline & & small bowel fecal matter & & \\
\hline \multirow{4}{*}{ Impending perforation } & & no & yes & \multirow{4}{*}{0.592} \\
\hline & no & 5 & 2 & \\
\hline & yes & 3 & 4 & \\
\hline & & bowel wall air (gangaeren) & & \\
\hline \multirow{3}{*}{ Impending perforation } & & no & yes & \multirow{3}{*}{1} \\
\hline & no & 7 & 0 & \\
\hline & yes & 6 & 1 & \\
\hline
\end{tabular}

Table 5. Five years Overall Survival and Event Free Survival among patients with intestinal obstruction versus patients with intestinal perforation.

\begin{tabular}{|c|c|c|c|c|c|c|c|c|c|c|}
\hline surgery Type & Total N & $\mathbf{N}$ of Deaths & Median FU Duration & 5 years OS & SE & p-value & N of events & 5 years EFS & SE & p-value \\
\hline Perforation & 14 & 4 & 34 & 0.629 & 0.166 & \multirow{2}{*}{0.08} & 5 & 0.536 & 0.179 & \multirow{2}{*}{0.153} \\
\hline Obstruction & 20 & 2 & 58 & 0.877 & 0.082 & & 4 & 0.751 & 0.112 & \\
\hline
\end{tabular}



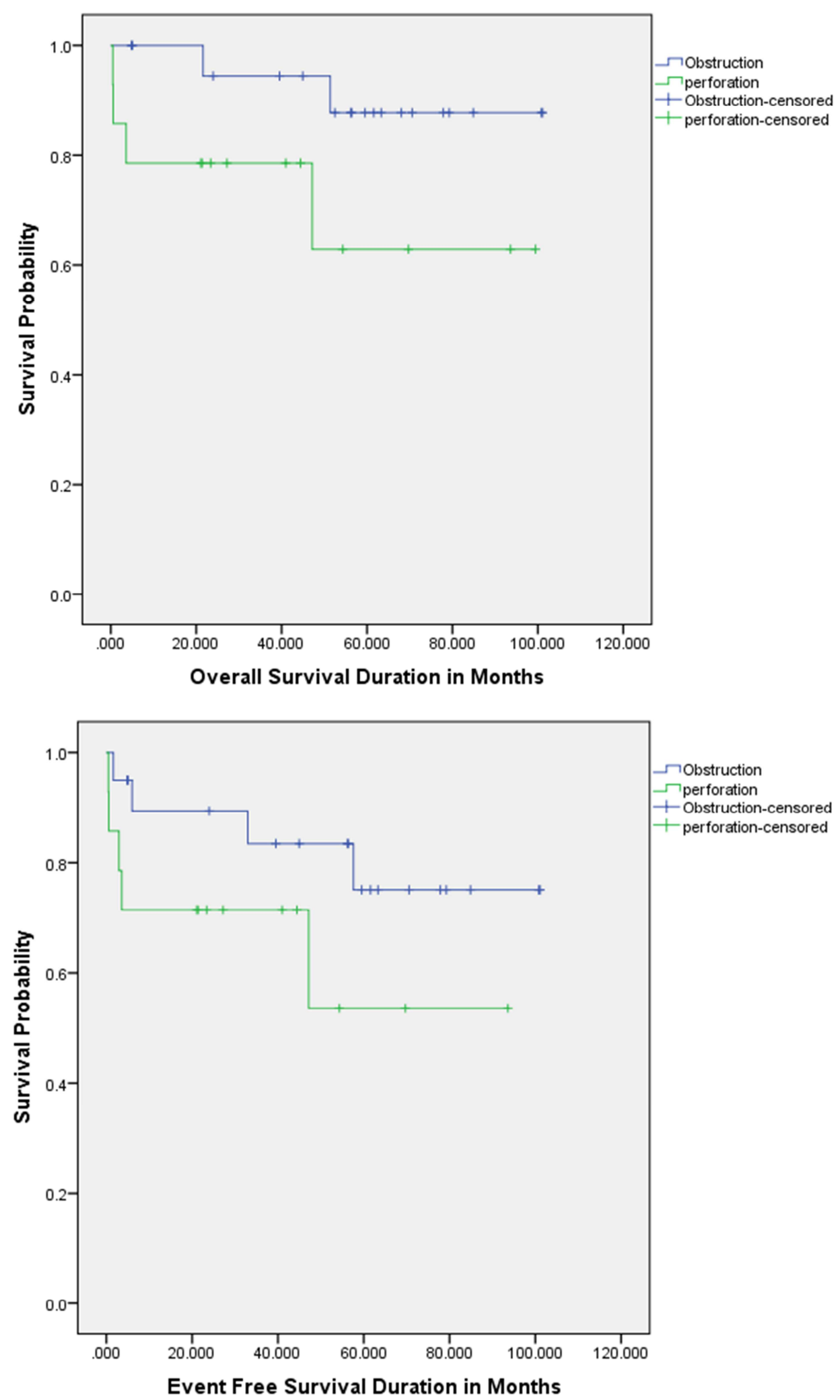

Figure 1. Five years Overall Survival and Event Free Survival among patients with intestinal obstruction versus patients with intestinal perforation.

Table 6. Overall Survival and Event Free Survival among patients with viable tissue versus patients with no viable tissue.

\begin{tabular}{lllllllllll}
\hline $\begin{array}{l}\text { Viability post } \\
\text { surgery }\end{array}$ & Total N & N of Deaths & Median FU Duration & $\begin{array}{l}\mathbf{5} \text { years } \\
\text { OS }\end{array}$ & SE & p-value & $\begin{array}{l}\text { N of } \\
\text { events }\end{array}$ & $\begin{array}{l}\text { 5 years } \\
\text { EFS }\end{array}$ & SE & p-value \\
\hline Viable & 16 & 5 & 46 & 0.652 & 0.130 & \multirow{2}{*}{0.049} & 7 & 0.482 & 0.144 & 0.059 \\
Not viable & 18 & 1 & 55 & 0.909 & 0.087 & & 2 & 0.889 & 0.074 & 0.059 \\
\hline
\end{tabular}



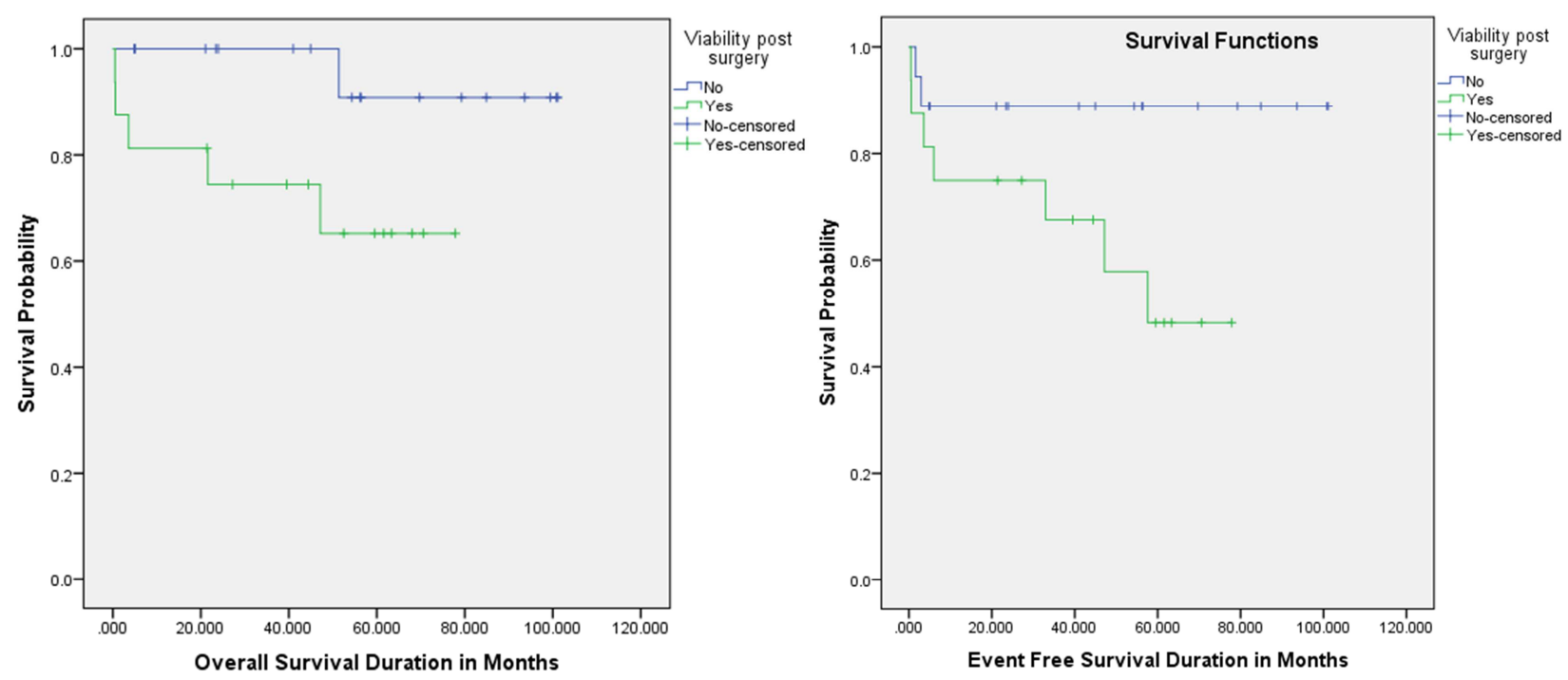

Figure 2. Overall Survival and Event Free Survival among patients with viable tissue versus patients with no viable tissue.

Table 7. Five years Overall Survival and Event Free Survival among patients with intestinal mature B cell lymphoma with surgery out of intestinal obstruction or perforation versus no surgery.

\begin{tabular}{|c|c|c|c|c|c|c|c|c|c|c|}
\hline surgery & Total N & $\begin{array}{l}\text { Nof } \\
\text { Deaths }\end{array}$ & Median FU Duration in $M$ & $\begin{array}{l}5 \text { years } \\
\text { OS }\end{array}$ & SE & p-value & $\mathrm{N}$ of events & $\begin{array}{l}5 \text { years } \\
\text { EFS }\end{array}$ & SE & p-value \\
\hline \multirow{2}{*}{$\begin{array}{l}\text { Non- surgical } \\
\text { surgical }\end{array}$} & 456 & 53 & 48 & $87.9 \%$ & \multirow[t]{2}{*}{0.016} & 0.323 & 65 & $85.4 \%$ & \multirow[t]{2}{*}{0.017} & 0.055 \\
\hline & 34 & 6 & 52 & $78.6 \%$ & & 0.080 & 9 & $67.2 \%$ & & 0.097 \\
\hline
\end{tabular}
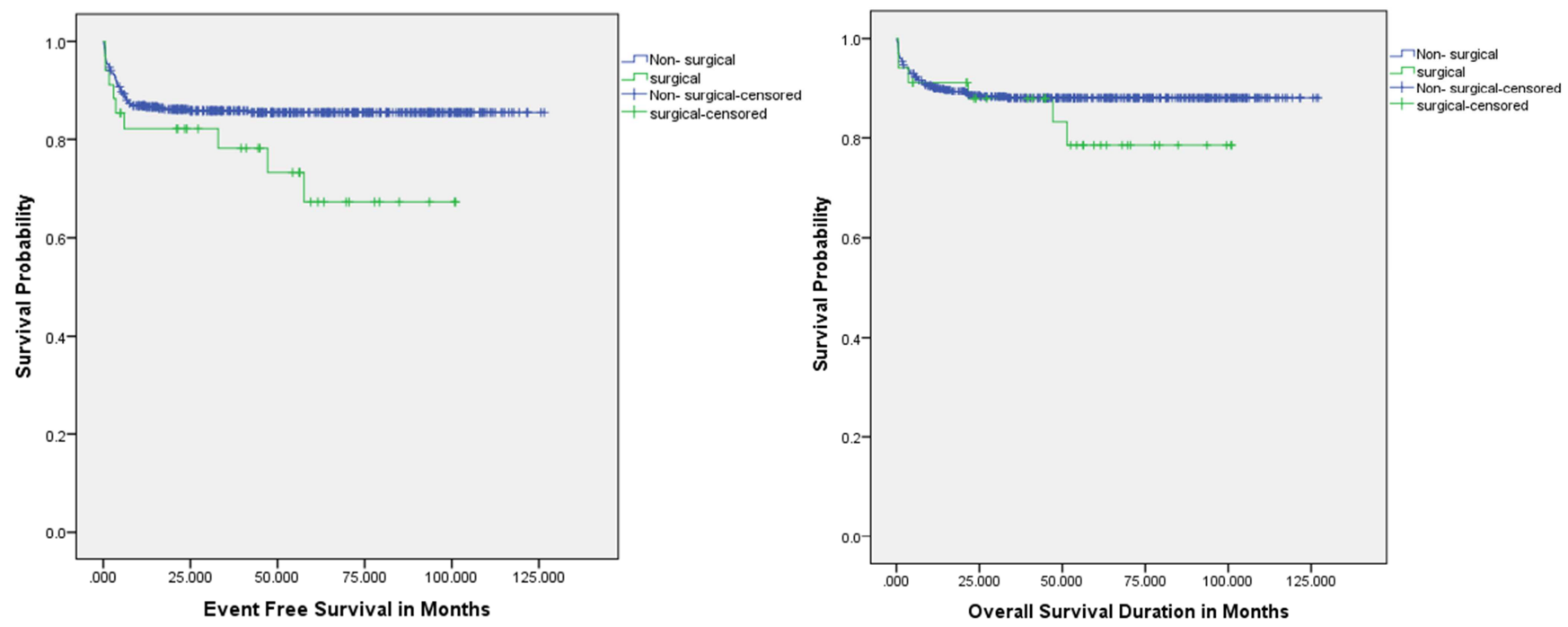

Figure 3. Overall Survival and Event Free Survival among patients with intestinal mature B cell lymphoma with surgery out of intestinal obstruction or perforation versus no surgery.

\section{Discussion}

Bowel perforation and obstruction are serious lifethreatening complications of lymphoma involving the gastrointestinal tract [3]. Intestinal obstruction or intussusception is caused by pressure phenomena, direct involvement of the bowel lumen or occur after initiation of chemotherapy.

In the current study the prognostic factors and outcome of pediatric patients with intestinal mature B cell lymphoma who were complicated with intestinal obstruction with or without intussusception, or with intestinal obstruction with perforation and operated during their NHL BFM 96 chemotherapy protocol[1] was examined. The incidence of perforation in pediatric intestinal mature B cell lymphoma is $9 \%$ [4]. We demonstrated that $7.5 \%$ of our pediatric patients with intestinal mature B cell lymphoma were operated out of intestinal complications. The peak age for pediatric gastrointestinal tract NHL is $5-15$ years [5]. In the current study, the median age of the subgroup is 4.85 years as that of the overall group which is 5.5 years.

The male to female ratio of childhood gastrointestinal NHL is reported to be from 7:1 to $1.8-2.5: 1[6,7,8,9]$. As 
in the current study as Male gender had the upper hand in both the subgroup patients, and the overall group patients which the ratio is $1.8: 1,3.5: 1$ respectively.

A higher prevalence of DLBCL is found in pediatric intestinal mature B cell lymphoma compared to other series $[4,10]$. That is against our finding in CCHE as the higher prevalence of Burkitt's lymphoma is found which account $95.4 \%$ of the cases in the overall group, and Burkitt's lymphoma was the pathology of all the subgroup patients.

BL is generally arises in the abdomen as stage III, head and neck region and presents as advanced-stage disease involving the $\mathrm{BM}$ and/or CNS in approximately $20 \%$ to $25 \%$ of patients [11]. As in the current study, stage III according to Ann Arbor stage had the upper hand in both the subgroup patients, and the overall group patients.BM and CNS involvement account $11.8 \%$ in the subgroup and about $12.1 \%$ in the overall group with no significant $\mathrm{P}$ value.

Lactate dehydrogenase (LDH) as a tumor bulk indicator [12] which was above the double of normal value in $29.4 \%$ among the subgroup patients and in $43.6 \%$ among the overall group patients with no significant $\mathrm{P}$ value. Acute tumor lysis syndrome (ATLS) was commonly seen in Burkitt's subtype of B-cell lymphoma. Higher LDH and large tumor sizes and kidney involvement were important risk factors for the development of ATLS in children with B-cell lymphoma [13] In Huang S1, et al, 2011, 18 cases out of 103 cases were diagnosed as having ATLS (17.5\%). All the 18 cases with ATLS were histo-pathologically confirmed as having Burkitt's lymphoma. All the patients were at stage III or IV and all had large tumor sizes, as in the current study, about $17.7 \%$ out of the subgroup patients, and about $16 \%$ of overall group patients had ATLS, with no significant $P$ value.

All intestinal mature B cell lymphoma patients were treated according to LMB 96 protocol [1] in our center, and about $82.4 \%$ out of the subgroup, and about $84.2 \%$ out of the overall group treated as group B with no significant $\mathrm{P}$ value.

In the current study, Multivariate analysis on event-free survival and overall survival was done. Analysis was performed both for the overall group and for the subgroup. Including age, sex, pathology, clinical stage, and group according to chemotherapy protocol, elevated $\mathrm{LDH}$, presence of ATLS, showed statically no significance.

Bowel complications were occurred in $14.7 \%$ out of the subgroup patients early before starting chemotherapy, and about $50 \%$ of the subgroup patients were operated at prophase and induction phase chemotherapy as in Goldberg SR1[14], who concluded that chemotherapy-induced intestinal perforation after treatment for Burkitt's lymphoma is a known potential complication.

Twenty patients were complicated and operated out of intestinal obstruction with or without intussusception, and 14 patients were complicated and operated out of perforation, the 5 years OS, and EFS among the 2 groups were with no significant statistical differences meaning that the cause of operation did not affect the outcome of the patients.

The Ileum is the most common site $(60 \%-65 \%)$ involving small intestine lymphoma [15], as in the current study as the ileum and ileocecal regions were the sites of bowel complication. Multivariate analysis on causes of impending perforation diagnosed by $\mathrm{CT}$ for the intestinal B cell lymphoma patients with perforation. Including aneurysmal dilatation at time of initial presentation, presence of pneumoperitonium, free abdominal fluid, proximal dilatation, small bowel fecal matter, presence of gangrenous loop, showed statistical no significance, because of several finding presented by $\mathrm{CT}$ and small number of cases.

Pathology was done for all resected intestinal loops, the half of them had viable tissue for malignancy, and the other half had no viable tissue. The 5 years OS among the patients with positive viable tissue for malignancy versus whom with negative viable tissue for malignancy was with significant $P$ value. Meaning that operation with viable malignant cell was associated with lower outcome.

5 years OS and EFS for intestinal mature B cell lymphoma patients who didn't have surgery, and among who had surgery were with no significant statistical differences, meaning that intestinal complication and exploration are not adverse prognostic factor for survival in pediatric patients with intestinal mature B cell lymphoma, that is against Natalie L, et al [16], who said that intestinal perforation associated with abdominal lymphomas in children portends an extremely poor prognosis.

\section{Conclusion}

In Children Cancer Hospital Egypt, there was about 7.5\% of pediatric patients with intestinal Burkitt lymphoma were operated out of intestinal complications. Multivariate analysis on event-free survival and overall survival was done, including age, sex, pathology, clinical stage, elevated LDH, presence of ATLS, showed statically no significance. Multivariate analysis on causes of impending perforation diagnosed by CT was done, showed statistical no significance, because of several finding presented by $\mathrm{CT}$ and small number of cases. Intestinal complication in the form of obstruction with or without intussusception, or obstruction perforation followed by exploration is not adverse prognostic affecting the overall survival or event free survival in pediatric patients with intestinal mature B cell lymphoma. Operation with viable malignant cell was associated with lower outcome.

\section{Acknowledgements}

I gratefully acknowledge my colleagues in NHL study team member in Children Cancer Hospital Egypt, and my patients.

\section{References}

[1] Mitchell S. Cairo, Mary Gerrard, Richard Sposto, et al on behalf of the FAB LMB96 International Study Committee, Results of a randomized international study of high-risk central nervous system B non-Hodgkin lymphoma and B acute lymphoblastic leukemia in children and adolescents, Blood 2007 109:27362743; doi: https: //doi.org/10.1182/blood-2006-07-036665. 
[2] David M. Biko1, Sudha A. Anupindi2, Andrea Hernandez2, et al, Childhood Burkitt Lymphoma: Abdominal and Pelvic Imaging Findings, American Journal of Roentgenology. 2009; 192: 1304-1315. 10.2214/AJR.08.1476

[3] A Shad, I Magrath: Malignant non-Hodgkin's lymphomas in children.PA Pizzo, DG Poplack (Eds.), Principles and Practice of Pediatric Oncology, Lippincott-Raven Publishers, Philadelphia, PA (1997), pp. 545-587.

[4] Vaidya R1, Habermann TM, Donohue JH, et al, Bowel perforation in intestinal lymphoma: incidence and clinical features. Ann Oncol. 2013 Sep; 24 (9): 2439-43.

[5] Bethel CA, Bhattacharyya N, Hutchinson C, Ruymann F, Cooney DR. Alimentary tract malignancies in children. J Pediatr Surg. 1997; 32: 1004-8.

[6] G.W.van ImhoffaI.M.AppelcN.J.G.M.Veegerd, et al, Gender and age-related differences in Burkitt lymphoma epidemiological and clinical data from The Netherlands, European Journal of Cancer Volume 40, Issue 18, December 2004, Pages 2781-2787.

[7] Mitchell S. Cairo, Richard Sposto, Mary Gerrard, et al, Advanced Stage, Increased Lactate Dehydrogenase, and Primary Site, but Not Adolescent Age ( $\geq 15$ Years), Are Associated With an Increased Risk of Treatment Failure in Children and Adolescents With Mature B-Cell Non-Hodgkin's Lymphoma: Results of the FAB LMB 96 Study, J Clin Oncol. 2012 Feb 1; 30 (4): 387-393.

[8] Ladd AP, Grosfeld JL. Gastrointestinal tumors in children and adolescents. Semin Pediatr Surg. 2006; 15: 37-47.

[9] Morsi A, Abd El-Ghani Ael-G, El-Shafiey M, Fawzy M, Ismail $\mathrm{H}$, Monir M. Clinico-pathological features and outcome of management of pediatric gastrointestinal lymphoma. J Egypt Natl Canc Inst. 2005; 17: 251-9.

[10] Ranjana Bandyopadhyay, Swapan Kumar Sinha,1 Uttara Chatterjee,1, et al, Primary pediatric gastrointestinal lymphoma. Indian J Med Paediatr Oncol. 2011 Apr-Jun; 32 (2): $92-95$.

[11] Véronique Minard-Colin, Laurence Brugières, Alfred Reiter, Non-Hodgkin Lymphoma in Children and Adolescents: Progress Through Effective Collaboration, Current Knowledge, and Challenges Ahead. J Clin Oncol. 2015 Sep 20; 33 (27): 2963-2974.

[12] Galleze A 12 Raache R 12 Cherif N, et al. Increased Level of Lactate Dehydrogenase Correlates with Disease Growth in Algerian Children with Lymphoma. Journal of Hematology and Oncology Research, ISSN: 2372-6601, Volume No: 2 Issue No: 4.

[13] Huang S1, Yang J, Zhang R, et al, [Clinical analysis of 18 cases with acute tumor lysis syndrome in children with B-cell lymphoma]. Zhonghua Er Ke Za Zhi. 2011 Aug; 49 (8): 622-5.

[14] Goldberg SR1, Godder K, Lanning DA. Successful treatment of a bowel perforation after chemotherapy for Burkitt lymphoma. J Pediatr Surg. 2007 Mar; 42 (3): E1-3.

[15] Samir Ranjan Nayak, 1,* Ganni Bhaskara Rao, 1 Subramanya Sarma Yerraguntla et al, Jejunal Perforation: A Rare Presentation of Burkitt's Lymphoma-Successful Management. Case Rep Oncol Med. 2014; 2014: 538359.

[16] Natalie L, Yanchar, JuanBass. Poor outcome of gastrointestinal perforations associated with childhood abdominal non-Hodgkin's lymphoma. Journal of Pediatric Surgery,Volume 34, Issue 7, July 1999, Pages 1169-1174. 